\title{
On the arrangement of two experimental activities on a novel multi- purpose floating structure concept
}

\author{
C. Ruzzo, A. Romolo, G. Malara \& F. Arena \\ Natural Ocean Engineering Laboratory (NOEL), Mediterranea University of Reggio Calabria Reggio \\ Calabria, Italy \\ F. Taruffi, S. Muggiasca \& M. Belloli \\ Politecnico di Milano Milano, Italy \\ B. Bouscasse, J. Ohana \\ Ecole Centrale de Nantes, Experimental facilities for Hydrodynamics and Ocean Engineering Nantes, France
}

A. Santoro

Wavenergy.it s.r.l. Reggio Calabria, Italy

K. Aubriere

Safier Ingenierie SaS Paris, France

G. Brizzi

Chlamys s.r.l. Trani, Italy

M. Collu

Department of Naval Architecture, Ocean and Marine Engineering, University of Strathclyde, Glasgow, UK

P. Corvaglia \& F. Lagasco

RINA Consulting S.p.A., Genova, Italy

ABSTRACT: "The Blue Growth Farm" is an ongoing H2020 European project, aimed to the development, engineering and demonstration of a new floating multi-purpose platform concept, devoted to aquaculture, and wind-wave energy production. Due to the significant complexity of the coupled dynamic behavior of the proposed concept, model tests are essential to investigate the most relevant physical phenomena and validate/calibrate the pertinent numerical models. However, the realization of a scaled model of such structure is by itself quite challenging, since each sub-system follows its own scaling laws and requires different strategies to minimize scale effects. The aim of the present paper is to describe the arrangement of the experimental activities, discussing the mechanisms of the scale factor at different scales and related results accuracy, scaling strategies and test environments. The two-phase framework and the scaling strategies proposed may be also useful for future activities on similar concepts.

\section{INTRODUCTION}

Blue Growth is the long-term European strategy to support sustainable growth in marine and maritime sectors as a whole. Oceans are indeed a great and mainly unexplored resource, whose sustainable use is expected to grow significantly in the next years and decades. In particular, offshore aquaculture and renewable energy production, especially in a combined hosting structure, are promising candidate solutions. Indeed, food and energy requests are growing sharply and open-sea may potentially provide vast areas, no land occupation, favorable met-ocean conditions (energetic wind and waves, currents for water recirculation in fish cages, etc.), and reduced visual and environmental impacts. On the other side, new technologies are required to guarantee technoeconomic feasibility and effectiveness. Over the past decade, a number of research projects have been funded by the European Community (FP7 and
$\mathrm{H} 2020$ ), in order to investigate the feasibility of large offshore multi-use/multi-purpose platforms for the sustainable use of the oceans. Among them, one could mention TROPOS, Mermaid, H2Ocean, MARINA, and others (Abhinav et al., 2020). While a number of platforms have been previously proposed and investigated, there is now the push to raise the Technology Readiness Level (TRL) of such concepts, by testing the proposed multi-purpose system in a relevant environment.

In this context, "The Blue Growth Farm" (BGF) (H2020, GA n. 774426) is aimed to develop an efficient, cost-competitive and environmentally friendly multi-purpose floating offshore platform, devoted to aquaculture and wind-wave energy production (Lagasco et al, 2019). An innovative concept has been developed within the project: a large modular moored concrete caisson-based platform with a rectangular moonpool, containing fish cages. The DTU 10 MW offshore wind turbine (Bak et al., 2013) is 
considered as a reference for the project studies to produce on site electric energy from wind, in conjunction with a certain number of oscillating water column (OWC) wave energy converters (WECs). The latter are based on the REWEC3 patented concept (Boccotti, 2002), and considered in the overall conception as embedded in the frontal breakwater. The fish cages take advantage of the protected internal pool, as well as the wave energy absorbed by the WECs. They share the floater and the mooring system with the platform, whilst providing additional damping to the floating platform. The integration of the sub-systems provides evident advantages from functional and economic points of view, but it increases significantly the complexity of the coupled system dynamics. A nonlinear aero-hydro-servoelastic numerical model has been developed within the project ( $\mathrm{Li}$ et al., 2019, 2020b; Ruzzo et al., 2019), and further studies are ongoing to refine the numerical results. In this context, pertinent experimental data are essential for its validation and calibration, hence two experimental activities have been arranged. The first one was concluded in October 2019 at the "Hydrodynamics and Ocean Engineering Tank" at École Centrale de Nantes (France) by a 1:40 scaled configuration. The model was tested in controlled conditions and several experimental data about the overall platform dynamics have been collected, as never achieved in the past. The measured data have been used to accomplish a first validation of the numerical model (Li et al., 2020a). The second one is planned to be performed at sea at the Natural Ocean Engineering Laboratory (NOEL) of Reggio Calabria (Italy), by a 1:15 scaled configuration. This activity will allow to achieve a more detailed representation of the structure and of its behavior, by accounting for the interaction between sub-system components in relevant environment. The present paper describes the arrangement of the two activities from a scaling point of view. The final target is to justify the appropriateness and correctness of the up-scaling methodology, as mostly representative to fine tune numerical models for the full scale predicted behavior.

The paper is organized as follows: Section 2 presents the floating platform concept and the two scaled models, Section 3-5 discuss in detail the scaling of wind turbine, WECs and fish nets, respectively. The importance of scale factor, scaling strategy and test environment is critically addressed in each case. Finally, conclusions are drawn, also with reference to future experimental activities on similar multi-purpose floating concepts.

\section{THE BLUE GROWTH FARM PLATFORM}

\subsection{Full-scale concept}

A sketch of the BGF multi-purpose platform concept is shown in Figure 1. The modular hull is protected by breakwaters and WECs in the forward side, while some openings are present in the aft side, to facilitate water recirculation, essential for fish health requirements. The cross section of the hull is Tshaped. This choice, based on extensive parametric studies, is aimed to: 1) enhance the natural periods of the vertical motions (Li et al, 2020b); 2) protect the inner moonpool; 3) promote modularity. The main characteristics of the platform are reported in Tables 1-3, with respect to dimensions, mass properties and mooring system, respectively. The mooring system is composed by four $90^{\circ}$-spaced sets of three mooring lines each, i.e. twelve mooring lines overall. Each line is made up of heavy chain and is inclined by about $45^{\circ}$ with respect to the platform (in plan view). The preliminary structural design of the full-scale platform has been carried out by the project partner Safier. Among the numerous engineering challenges imposed by such a new concept, the adequate representation of the coupled dynamics is quite important. The aim of the two experimental campaigns is to provide pertinent experimental data, in particular with reference to the moonpool dynamics and the coupling effects of wind turbine, wave energy converters and fish cages. It is relevant to note that, in spite of the relatively large dimensions of the full-scale floating platform, hydro-elastic numerical analyses have shown that elasticity could be neglected for the assessment of the overall dynamics (Ruzzo et al., 2019; Li et al., 2020b). Therefore, physical models of the floating support platform have been designed as rigid bodies. Froude scaling laws have been used for the design of the models, as reported in Table 4.

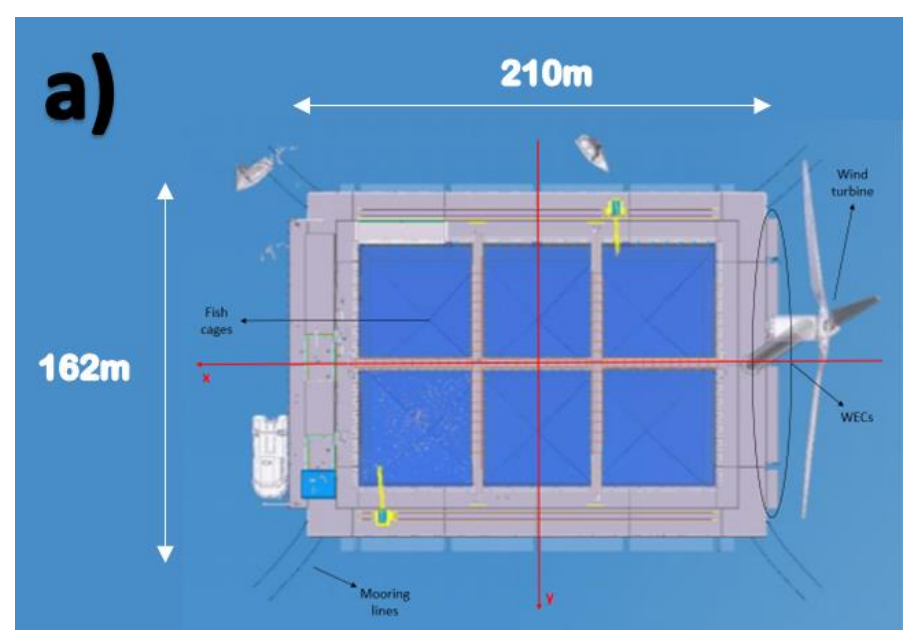



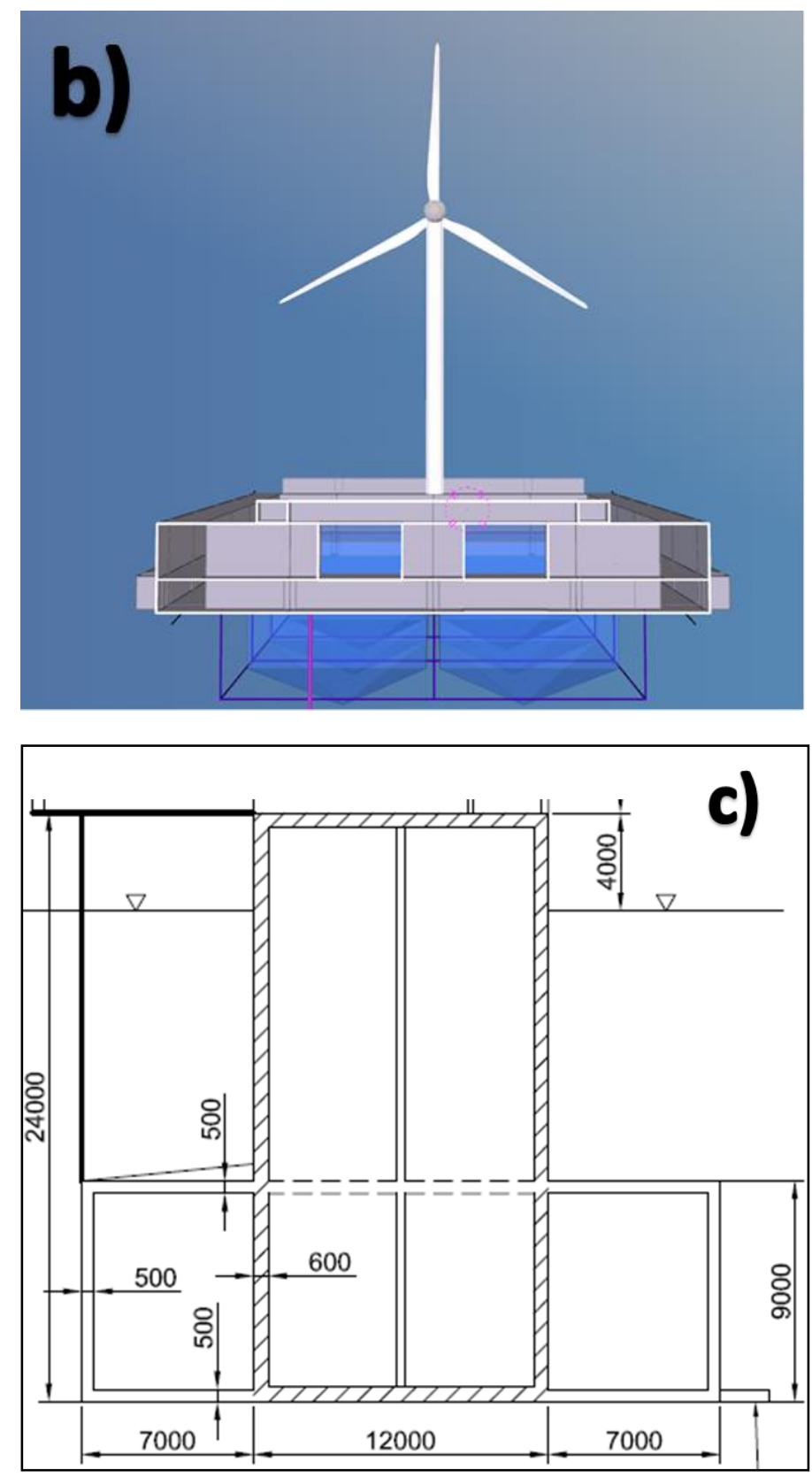

Figure 1. Multi-purpose concept. a) Plan view and definition of the reference system centered at the center of the moonpool. b) Front view. C) Typical cross section. Nota: the dimensions in the figure are referred to the full-scale platform. The scaled models' dimensions are given in Table 1 .

Table 1. Main dimensions of the BGF platform and its physical models.

\begin{tabular}{|c|c|c|c|c|}
\hline Parameter & $1: 1$ & $1: 40$ & $1: 15$ & Units \\
\hline Ext. size & $210 * 162$ & $5.25 * 4.05$ & $14.0 * 10.8$ & $\mathrm{~m}$ \\
\hline Moonpol size & $172 * 124$ & $4.30 * 3.10$ & $11.5 * 8.29$ & $\mathrm{~m}$ \\
\hline Draft & 20 & 0.49 & 1.333 & $\mathrm{~m}$ \\
\hline Walking plan quote & 4 & 0.1 & 0.267 & $\mathrm{~m}$ \\
\hline Breakwater quote & 8 & 0.2 & 0.534 & $\mathrm{~m}$ \\
\hline \multicolumn{2}{|c|}{ T Cross-section height9+15 } & $0.23+0.37$ & $0.6+1.0$ & $\mathrm{~m}$ \\
\hline \multicolumn{2}{|c|}{ T Cross-section width $12-26$} & $0.30-0.65$ & $0.8-1.734$ & $\mathrm{~m}$ \\
\hline Water depth & 100 & 5.00 & $\sim 37$ & $\mathrm{~m}$ \\
\hline
\end{tabular}

Table 2. Main mass properties of the BGF platform and its physical models. Moments of inertia are calculated about CoG.

\begin{tabular}{lllll}
\hline Parameter & $1: 1$ & $1: 40$ & $1: 15$ & Units \\
\hline Mass & $2.13 \mathrm{e} 8$ & 3384 & $6.31 \mathrm{e} 4$ & $\mathrm{~kg}$ \\
Moment of inertia $\mathrm{I}_{\mathrm{xx}}$ & $7.28 \mathrm{e} 8$ & 7.1 & 958.7 & $\mathrm{kgm}^{2}$ \\
Moment of inertia $\mathrm{I}_{\mathrm{yy}}$ & $1.09 \mathrm{e} 9$ & 10.6 & 1435 & $\mathrm{kgm}^{2}$
\end{tabular}

\begin{tabular}{lllll} 
Moment of inertia $\mathrm{I}_{\mathrm{zz}}$ & $1.80 \mathrm{e} 9$ & 17.6 & 2370 & $\mathrm{kgm}^{2}$ \\
CoG position $\mathrm{x}_{\mathrm{G}}$ & -10.5 & -0.26 & -0.70 & $\mathrm{~m}$ \\
CoG position $\mathrm{y}_{\mathrm{G}}$ & 0.0 & 0.00 & 0.00 & $\mathrm{~m}$ \\
CoG position $\mathrm{z}_{\mathrm{G}}$ & 2.6 & 0.07 & 0.17 & $\mathrm{~m}$ \\
\hline
\end{tabular}

Table 3. Main characteristics of the mooring system of the BGF platform and its physical models. Nota: 1:40 model is not achieved through scaled catenary, hence only few items are reported.

\begin{tabular}{lllll}
\hline Parameter & $1: 1$ & $1: 40$ & $1: 15^{*}$ & Units \\
\hline N. mooring lines & 12 & 4 & 4 & $\mathrm{~m}$ \\
Anchor depth & 100 & - & $4-57$ & $\mathrm{~m}$ \\
Fairlead quote & 4 & 0.1 & 0.167 & $\mathrm{~m}$ \\
Anchor-fairlead dist. & 817.7 & 20.4 & $92-118$ & $\mathrm{~m}$ \\
Line-X axis angle & 45 & 40 & $\sim 42$ & $\circ$ \\
Line length at equil. & 850 & $\sim 20.4$ & $100-135.6 \mathrm{~m}$ \\
Linear line mass & 401 & - & $11-199$ & $\mathrm{kgm}^{-1}$ \\
Axial line stiffness & $1.72 \mathrm{e} 8$ & - & $4.9-85.4 \mathrm{e} 7 \mathrm{~N}$ \\
Line equivalent diam. & 0.256 & - & $0.024-0.1 \mathrm{~m}$ \\
\hline
\end{tabular}

$\overline{\text { Table }} 4$. Froude scaling laws.

\begin{tabular}{lll}
\hline Parameter & Scale factor & Units \\
\hline Length/Height & $\lambda$ & $\mathrm{m}$ \\
Period & $\lambda^{0.5}$ & $\mathrm{~s}$ \\
Velocity & $\lambda^{0.5}$ & $\mathrm{~ms}^{-1}$ \\
Acceleration & 1 & $\mathrm{~ms}^{-2}$ \\
Frequency & $\lambda^{-0.5}$ & $\mathrm{rads}^{-1}$ \\
Angle & 1 & $\mathrm{rad}$ \\
Mass & $\lambda^{3}$ & $\mathrm{~kg}$ \\
Mass moment of inertia & $\lambda^{5}$ & $\mathrm{~kg} \mathrm{~m}^{2}$ \\
Force & $\lambda^{3}$ & $\mathrm{~N}$ \\
Moment & $\lambda^{4}$ & $\mathrm{Nm}$ \\
\hline
\end{tabular}

\section{$2.21: 40$ scaled physical model}

The first experimental campaign was carried out at the "Hydrodynamics and Ocean Engineering Tank" at École Centrale de Nantes (ECN), France, in October 2019. The tank comprises a testing volume of $30 \mathrm{~m} \times 50 \mathrm{~m} \times 5 \mathrm{~m}$ and allows testing both regular and irregular wave conditions. The 1:40 scale model (Fig. 2) was manufactured in steel, with dimensions and mass properties ensuring that Froude scaling laws were fulfilled, thanks also to the addition of opportune ballast inside the hull. The related information are shown in Tables 1-2. Due to the tank size, the mooring system was replaced by a system of four aerial lines, each made up of three segments (Fig. 2b): a set of springs (segment A), an elastic rope (segment B) and a Dyneema rigid rope (segment C). The stiffness of the lines was calibrated by ensuring that the quasi-static scaled forcedisplacement function of the overall mooring system matched the ideal scaled one as closely as possible (Fig. 3). 


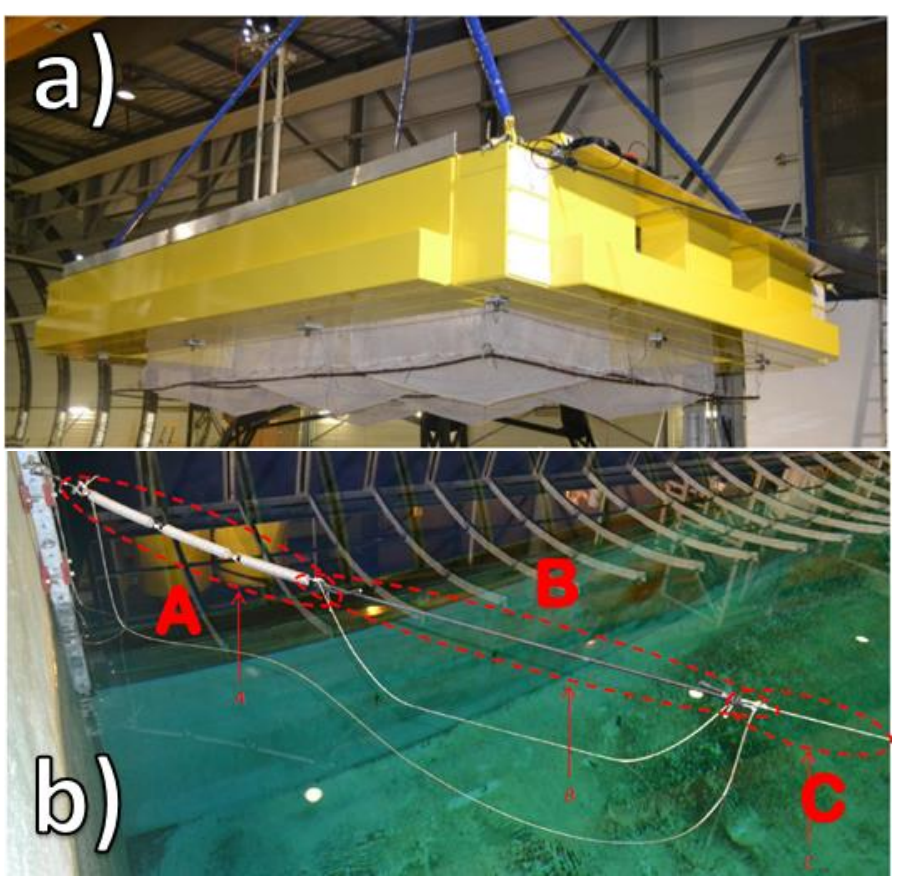

Figure 2. 1:40 scale model installed at ECN wave tank. a) Platform. b) Moorings: $\mathrm{A}=$ set of springs; $\mathrm{B}=$ elastic rope. $\mathrm{C}=$ Dyneema rigid rope

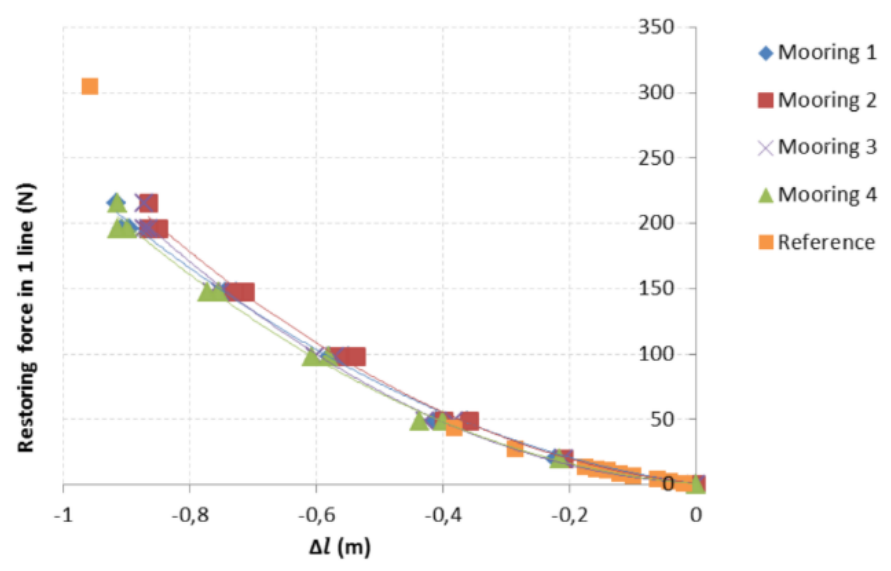

Figure 3. Measured quasi-static restoring force of each 1:40 mooring line versus reference scaled one.

The main characteristics of the scaled mooring system are summarized in Table 3. Additional details about the scaling of the other sub-systems are reported in the following sections.

Overall, 229 tests were performed. Pull out and free decay tests were performed in absence of wind and waves. Regular and irregular wave tests were performed for various wave directions $\left(0^{\circ}, 22.5^{\circ}\right.$, $45^{\circ}$ ), with and without wind. Steady and turbulent wind conditions were modeled through a hybrid Hardware-In-the-Loop (HIL) approach, as documented in section 3.2. Tests were repeated without fish nets and active WECs, with active WECs only and with both. A number of different sensors and equipment was used for measurements, as reported in Table 5.
Table 5. Sensors and equipment used during ECN experiment.

\begin{tabular}{lll}
\hline Sensor & n. & Scope \\
\hline Aerial tracking camera & 4 & 6-DOF motion tracking \\
Underwater video camera & 2 & Video records \\
Aerial video camera & 2 & Video records \\
PTZ video camera & 3 & Video records \\
Wave gauge & 6 & Wave elevation in the tank \\
Load cell & 4 & Mooring loads at fairleads \\
Wave gauge & 6 & Wave elevation in the nets \\
SBG IMU & 1 & WT flexible motions \\
2-DOF force sensor & 1 & WT tower top loads \\
6-DOF HBM force sensor & 1 & WT tower base loads \\
Wave gauge & 10 & WEC dynamics \\
Air pressure sensor & 5 & WEC dynamics \\
Underwater pressure sensor 1 & WEC dynamics \\
\hline
\end{tabular}

\section{$2.31: 15$ scaled physical model}

The second experimental campaign will be carried out at the "Natural Ocean Engineering Laboratory" (NOEL) of Reggio Calabria (Italy) between 202021 . The test site has unique geographical and metocean conditions, where pure wind-generated waves (JONSWAP-like spectra) with significant wave height $H_{s}$ and peak periods $T_{p}$ between $0.20-0.80 \mathrm{~m}$ and 2.0-3.6 s, respectively, occur quite regularly (Arena \& Barbaro, 2013). These sea states are pure Froude scale models of real ocean storms, which are very rare to be found in other sites, where small wind waves are usually superimposed to swells. Additional advantages of the site (Boccotti, 2014) are the small tide amplitude, the regularity of local wind, the water clarity and the variability of the available water depth, which make it particularly favorable for intermediate-scale activities on floating offshore structures. The natural wave generation reduces the cost of the activity and allows investigating a wider range of irregular input loads. On the other side, the uncontrolled environment requires new data analysis techniques and design constraint relative to local ultimate limit states, which are useless for scaling purposes but may affect the safety of the structure (Ruzzo et al., 2018).

The 1:15 scale model (Fig. 4) will be manufactured in steel and moored to the inclined seabed at NOEL site. The final design of the model is still ongoing, and it will account not only for scaling issues, but also safety, regulatory and environmental constraints. The latters are out of the scope of the present paper, hence only the former will be discussed. Geometric and mass properties of the structure are based on Froude scaling laws and are reported in Tables 1-2. Due to the local inclined seabed $\left(\sim 10^{\circ}\right)$, the characteristics of the mooring lines will be different between land-side (shorter, lighter) and seaside (longer, heavier, including additional nylon rope). Overall, four mooring lines will be installed, using two different types of studless chains, as shown in Table 3. It is noteworthy that, for safety 
purposes, the mooring system could be stiffer than the ideal scaled one, this will be taken into account in the numerical model validation phase, as well as the dynamic effects of the mooring lines, which could not be represented in the 1:40 model.

Tests will be performed with and without active WECs and cages. The 1:15 model is expected to provide further information with respect to the 1:40 one, including e.g.: 1) improved representation of the couplings between the sub-systems, as discussed in the next sections; 2) wider range of wave frequencies and heights allowing to investigate deeply nonlinearities and low-frequency effects; 3) longer duration of the campaign making probabilistic analyses feasible; 4) effect of the local currents on the fish cages.

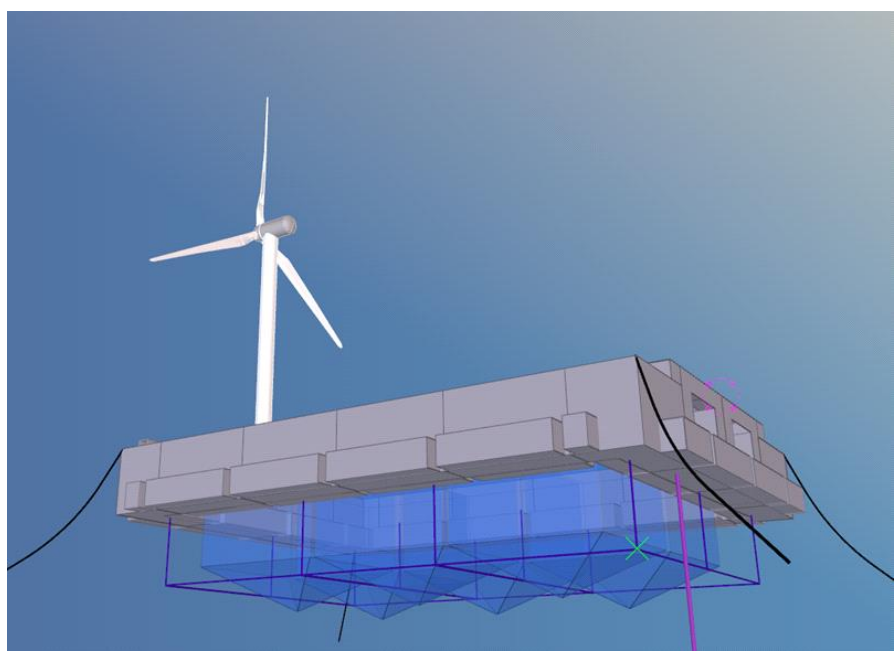

Figure 4. 1:15 scaled physical model for experiments at NOEL.

The list of sensors and equipment that will be used is shown in Table 6. A set of met-ocean sensors will be installed in the undisturbed field, to measure input environmental loads, using fixed poles on land (meteo-station) and offshore (wave, current). All the other sensors will be installed on-board. Load cells will be placed at all the fairleads and along at least a mooring line, to evaluate also the line dynamic forces. A variable number of pressure transducers, depending on the test layout (with or without cages), will be installed underwater all along the moonpool, to assess the inner wave field and the water exchange. A Structural Health Monitoring (SHM) system, based on Fiber Optic Sensors (FOS) technology and other integrated sensors, is implemented to evaluate either local or global platform deformation under external loadings. In particular, the proposed SHM will enable to measure a) local strain of the structural modules in the expected most critical sections; b) inclinations at a point of high platform stiffness; c) 3D accelerations. Wind turbine and WEC sensors will be described in more detail in the next sections.
Table 6. Sensors and equipment to be used during experiment at NOEL.

\begin{tabular}{lll}
\hline Sensor & n. & Scope \\
\hline Onboard thermo-camera & 1 & Video records, surveillance \\
Land video camera & 6 & Video records, surveillance \\
Ultrasonic probes & 2 & Undisturbed wave elevation \\
Pressure transducers & $2-6$ & Undisturbed wave field \\
Current profiler & 1 & Undisturbed current \\
Wind-meteo station & 1 & Undisturbed wind \\
Load cells & 6 & Mooring loads \\
Ultrasonic probes & 6 & Wave elevation at fish nets \\
Pressure transducers & $10-20$ Wave field inside moonpool \\
GPS tracking system & 1 & 3-DOF translational motions \\
AHRS inertial platform & 1 & 3-DOF rotational motions \\
SHM, opt. strain gauges & 4 & Uniaxial strain \\
SHM, opt. inclinometer & 2 & 3-DOF platform rotations \\
SHM, opt. accelerometer & 3 & 3-DOF accelerations \\
SHM, temper. sensors & 1 & Temperature compensation \\
Accelerometers & 9 & WT accelerations \\
Strain gauges & 1 & WT tower bending moment \\
Strain gauges & 3 & WT blade bending moment \\
Encoder & 1 & WT rotor speed \\
Encoder & 3 & WT blade pitch angles \\
Anemometer & 1 & Wind angle at rotor \\
Pressure transducers & $40-50$ WEC dynamics \\
\hline
\end{tabular}

\section{WIND TURBINE}

\subsection{Full-scale concept}

The full-scale wind turbine is based on the DTU 10 MW wind turbine, which is being used as reference design in a number of current research activities related to wind energy development, ranging from wind farm optimization to offshore wind turbine simulation or also for numerical tools benchmark and validation. The main properties are shown in Table 7 and a complete description can be found in Bak et al. (2013).

Table 7. Main characteristics of the wind turbine and its physical models.

\begin{tabular}{lllll}
\hline Parameter & $1: 1$ & $1: 40$ & $1: 15$ & Units \\
\hline Cut in wind speed & 4 & - & 1.75 & $\mathrm{~m} / \mathrm{s}$ \\
Cut out wind speed & 25 & - & 10.96 & $\mathrm{~m} / \mathrm{s}$ \\
Rated wind speed & 11.4 & - & 5 & $\mathrm{~m} / \mathrm{s}$ \\
Rotor Diameter & 178.3 & - & 6.86 & $\mathrm{~m}$ \\
Hub Height & 119 & 3.064 & 8 & $\mathrm{~m}$ \\
Max. Rotor Speed & 9.6 & - & 109.47 & $\mathrm{rpm}$ \\
Rated thrust force & 1500 & 0.02 & 0.5 & $\mathrm{kN}$ \\
RNA Mass & 674400 & 10.5 & 151 & $\mathrm{~kg}$ \\
Tower Mass & 628400 & 13.6 & 121 & $\mathrm{~kg}$ \\
$1^{\text {st }}$ bending fore-aft: & & & & \\
mode frequency & 0.285 & 1.85 & 1.1 & $\mathrm{~Hz}$ \\
Structural log damp. & 1.9 & 1.4 & - & $\%$ \\
\hline
\end{tabular}

\subsection{1:40 scaled physical model}

The scaling of the wind turbine in a multi-purpose floating structure is very challenging. This is mainly because aerodynamic loads are strongly dependent on Reynolds number, which is reduced in Froude /similarity by a factor of $\lambda^{1.5}$, being $\lambda$ the length scale factor. A Hardware-In-the-Loop (HIL) approach was 
used to get round the problem of simultaneous modelling of aerodynamic and hydrodynamic loads at reduced scale. By using an air turbine at the mast top, the need for reduced scaled rotor and blades and wind generation above the wave tank is eliminated, while keeping the main loads on the turbine properly scaled. This Software-In-the-Loop (SIL) system includes an embedded real time controller that runs an aero-servo simulation software to calculate the thrust to be generated by the controlled actuator. This thrust calculation takes into account the incident wind speed, its turbulence intensity, the real-time platform motions and the servo control law of the rotor. The estimated thrust was hence applied in real time to the ideal Rotor Nacelle Assembly (RNA) of the model, only by using a fan.

The system described in Arnal et al. (2019) is used to generate the wind thrust at the top of the tower. This experimental setup is made by a single actuator reproducing the mono-directional thrust. This actuator was previously calibrated to characterize its dynamic thrust generation capacities. The actuator is shown in Figure 5, mounted on the thrust force sensor, with its electronic drive. This system has the correct scaled mass and mass distribution, to represent faithfully the RNA weight and inertia.

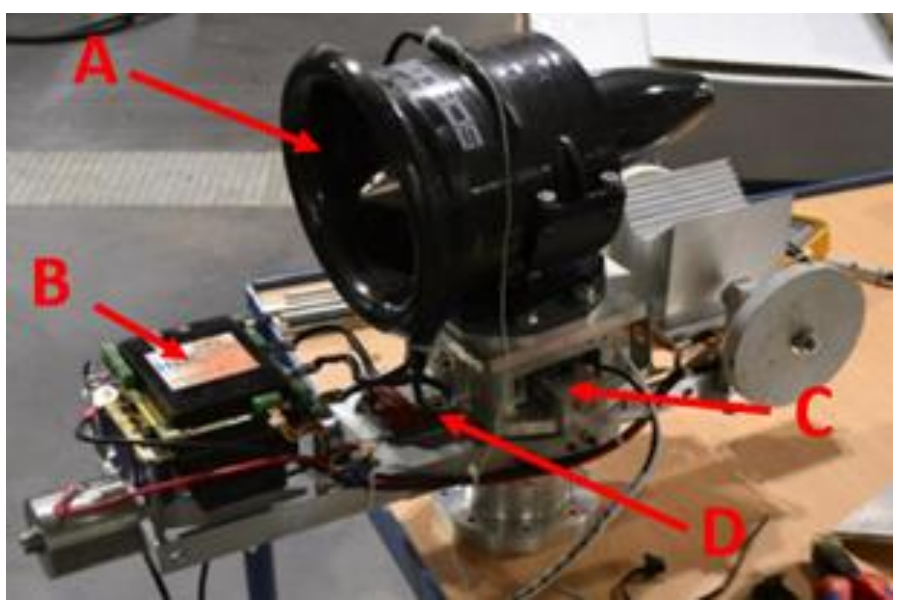

Figure 5. Model scaled turbine including: A) actuator; B) Motor drives; C) Thrust sensor; D) Inertial motion unit. The mounted wind turbine is shown in Figure 8, along with WECs.

The thrust calculation is based on a real-time numerical aero-servo simulation of the DTU $10 \mathrm{MW}$ wind turbine, with a slightly modified version of Open FAST v2.1, the NREL's tool for simulating the coupled dynamic response of wind turbines. The definition of the wind fields, the rotor and blades uses standard validated input files from the Life50plus project consortium (Pegalajar-Jurado, 2018). This numerical simulation is implemented on a National Instrument Compact RIO controller that enables a deterministic execution of the thrust calculation and a real time update of the thrust target to be sent to the turbine. For turbulent wind, the time series of wind velocity are generated with TurbSim (Jonk- man, 2009), using standard Kaimal spectra and given turbulence intensity levels.

The wind turbine tower was designed at full scale from the baseline DTU $10 \mathrm{MW}$ tower and scaled down according to Froude laws, using modal similitude for the $1^{\text {st }}$ bending mode (fore-aft and sideside). Wind turbine calibration tests, including hammer test, decay tests and step thrust loading of the actuator, have been used to compute the tower modal frequency, structural damping (Tab. 6). While using a real-time hybrid model testing setup, the flexible tower brings additional complexity. Indeed, measurements of bending motions (small amplitude and high frequency) with high accuracy and without noise are challenging. For that purpose, the data from the video motion capture system is combined with inertial motion unit measurements through a Kalman filter.

\subsection{1:15 scaled physical model}

The wind turbine outdoor scaled prototype (Fig. 6) is characterized by a scale $(1: 15)$ larger than the current standard for wind turbine scale models used for laboratory experiments $(\sim 1: 100)$. Hence, it has to satisfy, at the same time, the requirements of a laboratory aero-elastic scale model and of a real smallscale wind turbine. A performance scaling approach had to be used in order to obtain a mechanical system able to grant the same functionalities of the fullscale wind turbine under the expected environmental conditions at NOEL site. In particular, the interaction with the real-life environment, the safety in the laboratory area and the local wind characteristics had to be considered. Considering that Froude scaling is mandatory because the hydrodynamic interaction of the floater is driven by gravity, this criterion was used to scale the thrust force acting on the rotor, the masses and the tower aero-elastic parameters. It is worth noting that this performance scaling approach led to a smaller rotor, with respect to the geometrically scaled one. Other scaling approaches were considered to ensure the correct reproduction of the wind turbine rotor aerodynamics that has to face the difference in Reynolds number between the full-scale and prototype operation. The aerodynamics was re-designed for the purpose. The scaling approaches adopted and the aerodynamic design process can be found in Fontanella et al. (2019). 


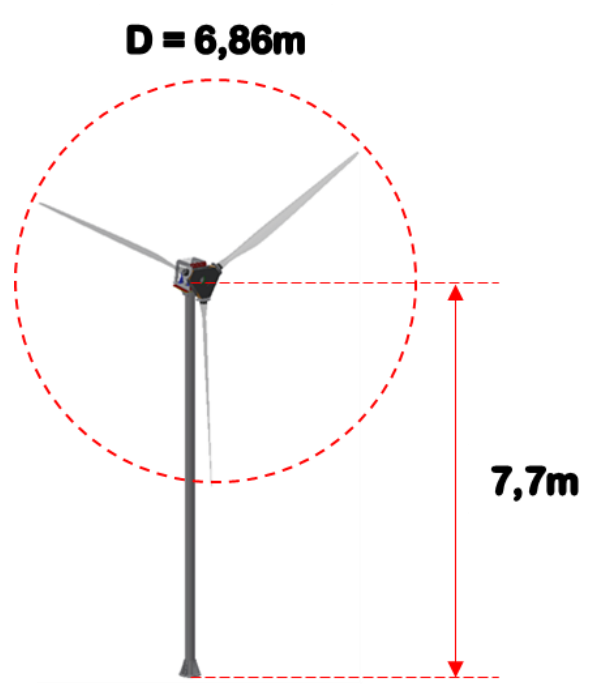

Figure 6. 1:15 wind turbine physical model CAD drawing.

The wind turbine model will be equipped with a control and monitoring system, actuators and sensors in order to ensure autonomous and continuous operation during tests. The mechatronic setup is based on five actuators: a main shaft motor, to control the rotor angular speed, three dedicated motors, allowing to control in real-time the individual pitch angle of each blade and a yaw actuator. The model will also be equipped with sensors including the main shaft encoder used as primary feedback for the wind turbine power controller. An embedded system is capable to control the actuators and acquire data from sensors simultaneously. A safety controller is included to monitor the operating parameters and manage faults. The wind turbine control logics is a VSVP (variable-speed variable pitch) derived from the full-scale turbine. The mechanical and mechatronic configuration of the turbine is deepened in Muggiasca et al. (2019).

\section{WAVE ENERGY CONVERTERS}

\subsection{Full-scale concept}

Full-scale WECs are based on a modified REWEC3 patented concept (Boccotti, 2002) for offshore applications. This is basically an OWC, comprising a chamber and an additional vertical U-duct, whose working principle is illustrated in Figure 7. The incident ocean waves induce a reciprocating motion of the water inside the U-duct, which generates alternately a compression and an expansion of the air pocket inside of the pneumatic chamber. Consequently, in the orifice connecting the chamber to the atmosphere, an alternating air flow is generated, that can drive an air turbine. The REWEC3 system can be equipped with a proper PTO for the production of electricity from pneumatic chambers. In particular, it is conceived to be equipped with a selfrectifying air turbine, connected to a generator.

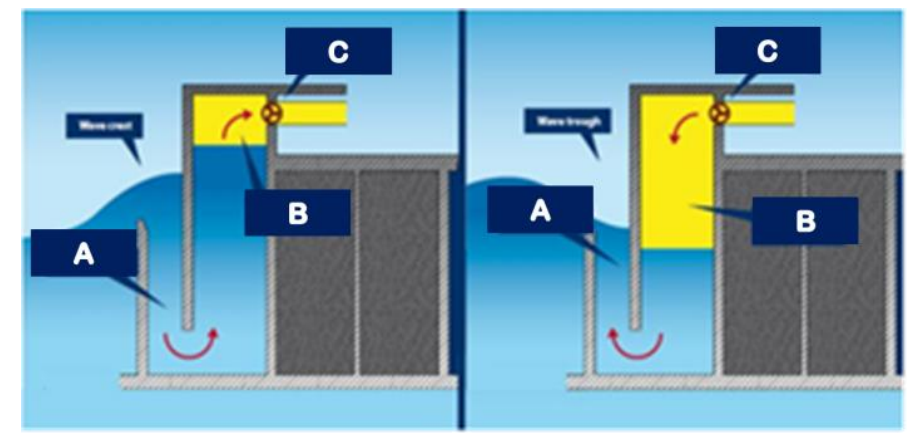

Figure 7. REWEC3 concept working principle. $\mathrm{A}=$ vertical $\mathrm{U}$ duct. $\mathrm{B}=$ air pocket. $\mathrm{C}=\mathrm{PTO}$.

The WECs are embedded in the frontal breakwater of the platform and their main characteristics are shown in Table 8. For the fullscale BGF platform, a location in the Central Mediterranean Sea has been chosen as case study. From a design perspective, the size of the active parts of the REWEC3 (U-OWC) system is defined, at this stage, so that the natural period of oscillation of the water column inside the pneumatic chamber has to be very close to the peak period of the most energetic sea states at the considered location. For the examined case, the device is designed to reach the resonance condition for sea states with peak period $T_{p}=7 \mathrm{~s}$ (significant wave height $H_{s}=2.7 \mathrm{~m}$ ), and it should work well at conditions very close to the resonance, i.e. for peak periods in the range among 6-8 $\mathrm{s}$. The design of the active parts ensured that the REWEC3 could absorb (on the average) 50$70 \%$ of the incident wave power.

The motion of the water column inside the U-duct and the chamber is modelled currently in literature by the application of the unsteady Bernoulli equation in conjunction with the linear water theory for the representation of the wave field in front of the structure. The wave pressure at the inlet is evaluated by the methods described in Boccotti (2007, 2012) and the head losses are accounted for using the model of Malara et al. (2017).

The available models have been applied to design an optimal configuration of the REWEC3, maximizing the average wave energy harvested by the device. The limitation of the present models is that they have been developed for fixed REWEC3 wave energy converters. Moreover, the design procedure has been implemented by considering a traditional self-rectifying Wells turbine (Curran \& Gato, 1997), without any optimization. More sophisticated solutions will be considered for the final design, as provided in Romolo et al. (2019). Based on the time-domain model of the power plant, the following data is computed for the turbines: i) the ideal turbine diameter; ii) the generator feedback control law aiming to maximize the turbine power output for turbine coupled to the REWEC3 device for Mediterranean applications. Sloshing phenomena 
were neglected based on previous experience on fixed REWEC3 studies, see e.g. those cited.

Finally, in the adopted design procedure, some constraints have been considered in terms of overall dimensions of the WEC due to structural requirements of the platform. Corner caissons of the platform, e.g., may present some different, not optimized WEC design, due to construction issues.

Table 8. Main characteristics of the WECs and their physical models.

\begin{tabular}{lllcc}
\hline Parameter & $1: 1$ & $1: 40$ & $1: 15$ & Units \\
\hline Chamber width $(x)$ & 390 & 10.00 & 28 & $\mathrm{~cm}$ \\
U-duct width $(x)$ & 190 & 5.85 & 13 & $\mathrm{~cm}$ \\
Duct opening depth & 200 & 5.00 & 13 & $\mathrm{~cm}$ \\
Horiz. duct height & 240 & 6.00 & 20 & $\mathrm{~cm}$ \\
Chamber width $(y)$ & 600 & 20.3 & $\sim 48$ & $\mathrm{~cm}$ \\
N. of chambers & 18 & 7 & 16 & - \\
Turbine diameter & 40 & 4.00 & 17 & $\mathrm{~cm}$ \\
N. of turbine holes & 12 & 7 & 16 & - \\
\hline
\end{tabular}

\section{$4.21: 40$ scaled physical model}

The U-OWC 1:40 models (Fig. 8) were designed by ensuring geometrical similarity with realistic fullscale plants. In this context, one of the critical elements to be designed is the small vertical duct on the wave beaten side, as it is used for tuning the eigenperiod of oscillation of the water column. This element was designed by keeping the duct width half of the chamber width, because it was observed that such a proportion leads to nearly maximum power absorption (Boccotti, 2012). The scaling of the air chamber is a quite challenging process. Indeed, the fact that both 1:40 model and 1:1 prototype operate in atmospheric conditions prohibits the interpretation of the model data via Froude similarity. For circumventing this limit, the use of deformed air chambers was proposed in the literature (Falcão and Henriques, 2014). However, this approach was not implemented in the experimental activity, because this would have led to an altered geometrical deformation of the overall BGF model and an unrealistic model mass distribution, whose dynamic response could not be used for inferring the 1:1 BGF platform behavior. The power-take-off (PTO) of the WECs included in this platform were modelled using a single calibrated hole for each PTO, as it is usually done when modelling OWC devices (Thiebaut et al. 2015). Despite the fact that Froude scale similarity was not fully exploited, the experimental model could be used for mathematical modelling purposes. Indeed, the air chamber pressures, the water column displacements and the exciting wave pressure at water column inlet (the latter only for one WEC) were measured by pressure transducers and resistive probes. Thus, allowing recording data about UOWC excitation and response, which will be used for model calibration/validation purposes.

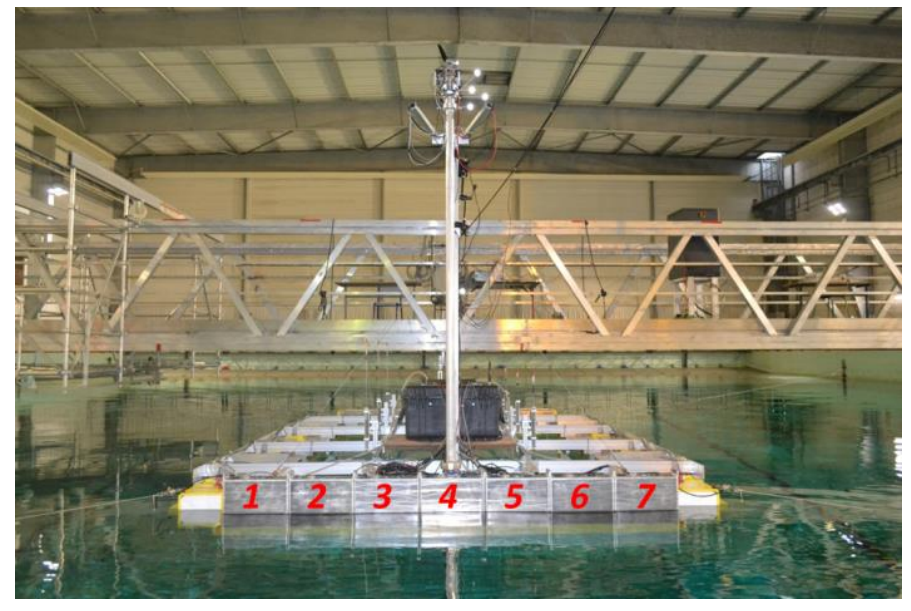

Figure 8. U-OWC WECs installed in the 1:40 scaled model.

\subsection{1:15 scaled physical model}

The REWEC3 1:15 scale model shows the same limitations discussed in the previous section. Indeed, scaling with the 1:15 proportion the size of the air chamber does not allow analyzing of the data recorded inside the WEC by Froude similarity. Based on these observations, the configuration of a 1:15 REWEC3 scale model with full external geometrical similarity with 1:1 prototype has been adopted. However, the active parts (U-duct and pneumatic chamber) have been properly designed to ensure the maximum energetic performances, in terms of absorbing power and pneumatic power made available by the floating REWEC3 to a PTO for the production of electricity. In this regard, the REWEC3 has been designed to reach the resonance condition under the most energetic sea states at NOEL characterized by peak periods in a range among 2-3 s. Moreover, to increase the mass flow rate of air through a PTO, and, thus, the related power output, a configuration with communicating adjacent cells has been adopted. In this way, the energy-wise performance of the REWEC3 increases significantly, approaching that of the full scale.

The experimental activities at NOEL will be the first ones to be carried out at a natural field on a floating REWEC3. Thus, limitation of past models and validation of the new model will be investigated.

The three elements of the U-OWC will be equipped with pressure transducers. The water column inlets will include one sensor providing information about the exciting wave pressure. The water column is equipped with three pressure transducers located at the center of the water column in a straight vertical row. They provide an indirect measure of the water column displacement. Then, a pressure transducer is installed in the air chamber for quantifying the air pressure values and the power output of the system. On the overall, this configuration allows describing the critical U-OWC response characteristics and calculating absorbed and converted (in the form of air mechanical energy) power. 


\section{FISH NETS}

\subsection{Full-scale concept}

Fish cages experience several advantages from the integration within the BGF platform. With respect to the traditional floating cages, floating collar and mooring system are not necessary, as these functions are carried out by the corresponding items of the platform. In addition, the cages are protected from environmental loads and automated aquaculture systems can be implemented, thanks to the local renewable energy production.

From a scaling point of view, the nets are responsible of drag dynamic forces transmitted to the platform, and the sinker tube weight and flexibility govern the net deformation. These quantities may have an important impact on the overall platform dynamics, particularly in terms of drag damping. The main characteristics of the cage components are reported in Table 9. Each net has a box shape in the upper part and an inverted-pyramid shape in the lower. Net and sinker are connected by a frame of ropes, which are not described in the present paper.

Table 9. Main characteristics of the fish cages of the BGF platform and its physical models.

\begin{tabular}{lllll}
\hline Parameter & $1: 1$ & $1: 40$ & $1: 15$ & Units \\
\hline N. of nets & 6 & 6 & 6 & - \\
Box sides & $50 * 50$ & $1.25 * 1.25$ & $3.33 * 3.33$ & $\mathrm{~m}$ \\
Box height & 35.5 & 0.8875 & 2.37 & $\mathrm{~m}$ \\
Pyramid height & 15 & 0.375 & 1 & $\mathrm{~m}$ \\
Net twine length & 20 & 9 & 12 & $\mathrm{~mm}$ \\
Net twine diameter & 3.3 & 1.5 & 2 & $\mathrm{~mm}$ \\
Sinker diameter & 500 & 15 & 25 & $\mathrm{~mm}$ \\
Sinker thickness & 55.8 & - & 3.4 & $\mathrm{~mm}^{-1}$ \\
Sinker linear weight & 100 & - & 0.45 & $\mathrm{kgm}^{-1}$ \\
Sinker Young modul. & 1050 & - & 200 & $\mathrm{MPa}$ \\
\hline
\end{tabular}

\section{$5.21: 40$ scaled physical model}

As per wind turbine and WECs, the scaling of fish nets is not completely possible following Froude scaling laws. First, the very small dimensions of the twine make at least unpractical the manufacturing of a real scale model. For the same reason, it is practically impossible to scale the elastic properties of the nets and the ropes. Finally, the hydrodynamic force coefficients of the twine depend on Reynolds number, which is affected by Froude scaling, as discussed in section 3.2. Therefore, several simplifications are needed. Under dynamic loads, the main forces transmitted to the floater by the fish nets are hydrodynamic forces. Although they are generally smaller than overall forces on the platform, drag forces may represent a non-negligible damping contribution in close-to-resonance conditions such as low-frequency motions, when the radiation damping of the platform is small. It is then important to achieve the best representation possible of these forces.

The external shape and dimensions of the 1:40 scale model of the fish nets (see Fig. 2 and Fig. 9) was obtained by applying directly Froude scaling laws to the full-scale design. It was not possible, however, to translate it to the mesh properties. Based on pertinent literature (see e.g. Kristiansen \& Faltinsen, 2012), the hydrodynamic forces can be represented by a screen model, where the net is regarded as a set of panels and hydrodynamic coefficients are dependent on solidity ratio $S$ and Reynolds number. The former can be defined as:

$$
S \equiv 2 \frac{d}{l}-\left(\frac{d}{l}\right)^{2},
$$

where $d, l$ are the twine diameter and length, respectively. Physically, solidity ratio represents the ratio between the projected net area on each "panel" and its total area. Based on this definition and on manufacturer availability, 1:40 fish nets were designed so as to keep the solidity ratio constant with respect to full-scale, i.e. about 0.3. It should be noted, however, that it was not possible to preserve also Reynolds number conditions, since high twine diameters values would have been required. In addition, the impact of hydrodynamic forces on low-frequency motions could not be evaluated due to the relatively short duration of the available recording slots.

Concerning the sinker frame, it was obtained by means of very small polyethylene tubes suspended through flexible bridles.

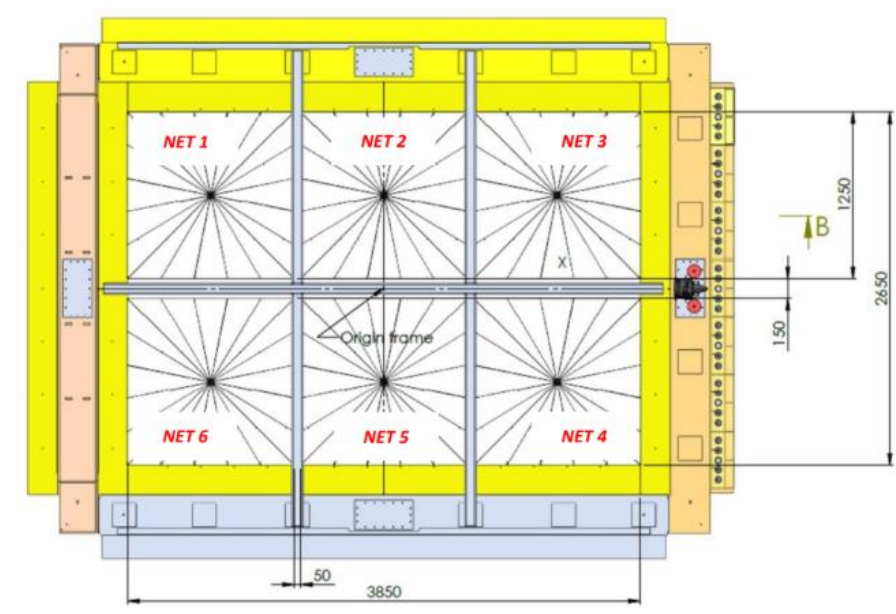

Figure 9. 1:40 cage models (plan view).

\subsection{1:15 scaled physical model}

The scaling strategy for the 1:15 scale model of the nets is similar to the 1:40 one. However, the larger scale allowed for more efficient net scaling. It is worth noting that the same net mesh was used for both models, while the range of Reynolds number varied because of the increase of the velocities. To 
investigate the impact of this effect, the relative velocities between the water and the nets have been obtained numerically for several met-ocean conditions and in different points. Reynolds number has been then determined as:

$$
R=\frac{v d}{(1-S) v},
$$

being $v$ the water kinematic viscosity, i.e. $10^{6}$ $\mathrm{m}^{2} \mathrm{~s}^{-1}$. Finally, the distortion of hydrodynamic coefficients, due to Reynolds number alteration, has been estimated. To exemplify, the results obtained for a given operational condition of the 1:15 scale model, i.e. wind-wave orthogonal to the breakwater, wind velocity of $5 \mathrm{~m} / \mathrm{s}$, significant wave height of $0.4 \mathrm{~m}$ and no current, are presented in the following. The ranges of Reynolds numbers obtained are: 1) 41769828 for the full-scale structure, $\sim 492-1158$ for the $1: 15$ scale model, and $\sim 301-709$ for the $1: 40$ scale model. Based on the empirical law proposed by Kristiansen and Faltinsen (2012), the reference drag coefficient of the net is shown in Figure 10 (solidity ratio is almost constant at all scales).

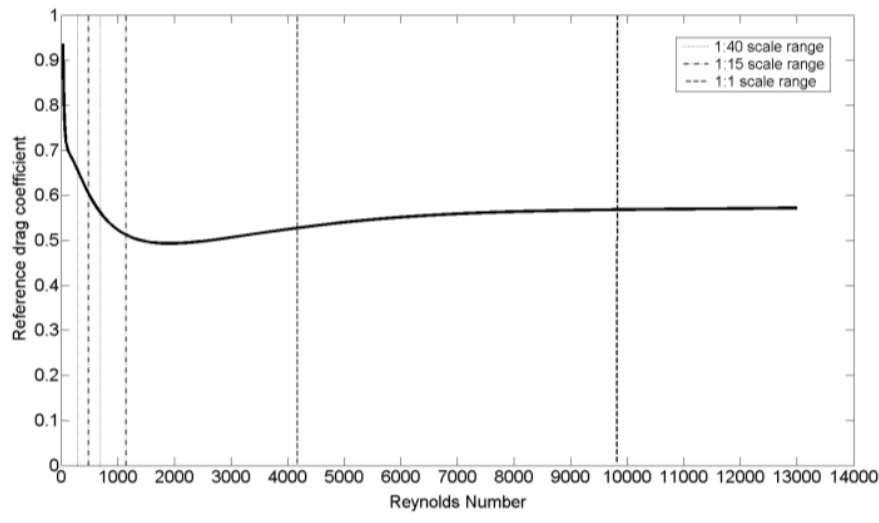

Figure 10. Reference drag coefficient of the net (actual drag coefficient is a function of direction and other parameters not affected by scaling, being $S$ constant)

It can be observed that the ranges of Reynolds numbers of the two models correspond to different ranges of reference drag coefficients. In particular, $0.65-0.56,0.60-0.51$ and $0.53-0.57$ have been obtained for $1: 40,1: 15$ and 1:1 scales, respectively, for the particular met-ocean condition considered. These ranges correspond to a local alteration of the reference drag coefficient variable along the net between $+23.6 \%$ and $-0.01 \%$ for the $1: 40$ scale model and $+14.1 \%$ and $-10.0 \%$ for the $1: 15$ scale model. In the 1:40 model, the overall drag force on the net is hence overestimated, while small differences are expected for the 1:15 scale model, since local alterations of the reference drag coefficients tend to compensate between each other. It is worth noting that drag reference coefficients tend to increase for smaller velocities (and vice-versa), especially for the 1:40 case where the curve of Figure 10 is steeper.
Finally, the 1:15 scale model of the sinker tube was based on Froude scaling of linear weight and bending stiffness $E I$, as well as from manufacturer availability (Tab. 9). External sinker diameter scaling does not follow perfectly Froude laws, but the resulting effect in terms of hydrodynamic forces reduction should be negligible with respect to the net total forces. The same applies to the suspension ropes.

\section{CONCLUSIONS}

This paper presented and discussed the arrangement of two experimental campaigns of an innovative multi-purpose floating platform concept, proposed within the Blue Growth Farm EU project (H2020, GA n. 774426). The coupled dynamic behavior of the platform is very complex because of the combined effects of moonpool, offshore wind turbine, WECs, and fish cages. Therefore, it is investigated by means of distinct scaled experiments. Specifically, two experimental activities were carried out in a wave tank (1:40 scale) and at sea (1:15 scale), respectively. Measured data from the latter experiment will be available next year. The details of the scaled physical models were presented and the effects of test environment, scale factor and scaling strategy for each sub-system discussed.

The smaller scale (1:40) activity was carried out in a controlled environment, where free-decay and regular wave tests are feasible, and the interpretation of experimental data is well controlled. These advantages are typical of indoor experiments, however limitations due to scale effects may apply as well, particularly for multi-purpose floating platform testing. Indeed, some of the sub-systems dynamics may strongly depend on viscous effects and therefore on the Reynolds number, which cannot be matched in an experimental campaign based on Froude law. This applies to the two case-studies presented in this paper. To circumvent these issues, a hybrid approach was used for the wind turbine modeling, by applying an opportune time-variant thrust to the 1:40 rotor model through an actuator. However, it was not possible to fulfil Froude scaling laws for WECs, whose dynamic effects has been over-simplified, and fish nets, whose drag coefficients dependence on Reynolds number has been neglected. The mooring has been simplified also, because the wave tank water depth was not scaled with the design condition. Furthermore, the choice of a spring system allows for easier comparison with the numerical model.

On the opposite side, 1:15 scale model allows to reduce scale effects, even though data postprocessing is more complex due to the noncontrolled environment. A physical model of the wind turbine has been designed, to reproduce the scaled thrust under the testing site specific met- 
ocean conditions. Similarly, the energy-wise performance of the WEC has been tuned by accounting the specific features of the local waves, via an adhoc design of the WEC geometry, including the use of a communicating-chamber configuration. Mooring system and fish nets have been designed to account for dynamic forces, taking into account Reynolds number effects for the latter. Finally, the longer duration of the test records and the better representation of damping properties will allow investigating low-frequency motions, which are expected to play an important role in the overall structure dynamics and could not be measured in 1:40 tests.

The overall framework proposed in the paper, i.e. the two-phase activity with increasing level of detail, can be useful for future experimental campaigns on similar concepts, where the proposed scaling strategy could be further addressed and validated.

\section{ACKNOWLEDGEMENTS}

This work has been produced in the framework of the Blue Growth Farm project (http://www.thebluegrowthfarm.eu/), which has received funding from the European Union's Horizon 2020 research and innovation programme under Grant Agreement number 774426. The content of the work does not report the opinion of the European Commission and reflects only the views of the author(s), including errors or omissions. The European Commission is also not liable for any use that may be made of the information contained herein.

\section{REFERENCES}

Abhinav, K.A., Collu, M., Benjamins, S., Cai, H., Hughes, A., Jiang, B., Jude, S., Leithead, W., Lin, C., Liu, H., RecaldeCamacho, L., Serpetti, N., Sun, K., Wilson, B., Yue, H., Zhou, B.Z. 2020. Offshore multi-purpose platforms for a Blue Growth: A technological, environmental and socioeconomic review. Science of the Total Environment 734, 138256.

Arena, F., Barbaro, G. 2013. The Natural Ocean engineering laboratory, NOEL, in Reggio Calabria, Italy: a commentary and announcement. Journal of Coastal Research 29 (5): vii-x.

Arnal, V., Bonnefoy, F., Gilloteaux, J.C., Aubrun, S. 2019. Hybrid model testing of floating wind turbines: test bench for system identification and performance assessment. Proceedings of the ASME $201938^{\text {th }}$ International Conference on Ocean, Offshore and Arctic Engineering, June 9-14, 2019, Glasgow, Scotland, UK. OMAE2019-96374.

Bak, C., Zahle, F., Bitsche, R., Kim, T., Yde, A., Henriksen, L.C., Natarajan, A., Hansen, M.H. 2013. Description of the DTU 10 MW Reference Wind Turbine. DTU Wind Energy Report-I-0092, July.

Boccotti, P. 2002. Caisson for absorbing wave energy. US Patents.

Boccotti, P. 2007. Caisson breakwaters embodying an OWC with a small opening - Part I: Theory. Ocean Engineering 34 (5-6), 806-819
Boccotti, P. 2012. Design of breakwater for conversion of wave energy into electrical energy. Ocean Engineering 51, $106-118$.

Boccotti, P. 2014. Wave Mechanics and Wave Loads on Marine Structures, first ed. Butterworth-Heinemann, Waltham.

Curran R., Gato, L.M.C. 1997. The energy conversion performance of several types of Wells turbine designs. Proceedings of the Institution of Mechanical Engineers, Part A: Journal of Power and Energy 211, 133-145.

Falcão, A.F.O., Henriques, J.C.C. 2014. Model-prototype similarity of oscillating-water-column wave energy converters. International Journal of Marine Energy 6, 18-34.

Fontanella, A., Taruffi, F., Muggiasca, S., Belloli, M. 2019. Design methodology for a floating offshore wind turbine large-scale outdoor prototype. Proceedings of the ASME $201938^{\text {th }}$ International Conference on Ocean, Offshore and Arctic Engineering, June 9-14, 2019, Glasgow, Scotland, UK. OMAE2019-95979.

Jonkman, B.J. 2009. TurbSim user's guide: Version 1.50. Technical Report NREL/TP-500-46198. National Renewable Energy Lab. (NREL), Golden, CO (United States).

Kristiansen, T, Faltinsen, O.M. 2012. Modelling of current loads on aquaculture net cages. Journal of Fluids and Structures 34, 218-235.

Lagasco, F., Collu, M., Mariotti, A., Safier, E., Arena, F., Atack, T., Brizzi, G., Tett, P., Santoro, A., Bourdier, S., Salcedo Fernandez, F., Muggiasca, S., Larrea, I. 2019. New engineering approach for the development and demonstration of a multi-purpose platform for the blue growth economy. Proceedings of the ASME $201938^{\text {th }}$ International Conference on Ocean, Offshore and Arctic Engineering, June 9-14, 2019, Glasgow, Scotland, UK. OMAE201996104.

Li, L., Collu, M., Abhinav, A.K., Ruzzo, C., Arena, F. 2019. Analysis of the coupled dynamics of an offshore floating multi-purpose platform, part A: rigid body analysis. Proceedings of the ASME $201938^{\text {th }}$ International Conference on Ocean, Offshore and Arctic Engineering, June 9-14, 2019, Glasgow, Scotland, UK. OMAE2019-96212.

Li, L., Collu, M., Ruzzo, C., Arena, F., Taruffi, F., Muggiasca, S., Belloli, M. 2020a. Development and validation of a coupled numerical model for offshore floating multipurpose platforms. Proceedings of the $4^{\text {th }}$ International Conference on renewable energies offshore (RENEW2020), October 12-15, 2020, Lisbon, Portugal.

Li, L., Ruzzo, C., Collu, M., Gao, Y., Failla, G., Arena, F. 2020b. Analysis of the Coupled Dynamic Response of an Offshore Floating Multi-Purpose Platform for the Blue Economy. Ocean Engineering: under review.

Malara, G., Romolo, A., Fiamma, V., Arena, F. 2017. On the Modelling of Water Column Oscillations in U-OWC Energy Harvesters. Renewable Energy 101, 964-972.

Muggiasca, S., Fontanella, A., Taruffi, F., Giberti, H., Facchinetti, A., Belloli, M., Bollati, M. 2019. Large Aeroelastic Model of a Floating Offshore Wind Turbine: Mechanical and Mechatronics Design. In: ASME $20192^{\text {nd }}$ International Offshore Wind Technical Conference. American Society of Mechanical Engineers Digital Collection.

Natural Ocean Engineering Laboratory (NOEL) website http://www.noel.unirc.it. Accessed: June 2020.

Pegalajar-Jurado, A. 2018. "LIFES50+ D4.5: State-of-the-art models for the two LIFES50+ 10MW floater concepts," DTU.

Romolo A., Henriques J., Gato L.M.C., Malara G., Laface V., Gomes R.P.F., Portillo, J.C.C., De Falcaõ A.F.O., Arena, F. 2019. Power take-off selection for a U-shaped OWC wave energy converter. Proceedings of the ASME $201938^{\text {th }}$ International Conference on Ocean, Offshore and Arctic Engineering, June 9-14, 2019, Glasgow, Scotland, UK. OMAE2019-96368. 
Ruzzo, C., Fiamma, V., Collu, M., Failla, G., Nava, V., Arena, F., 2018. On intermediate- scale open-sea experiments on floating offshore structures: feasibility and application on a spar support for offshore wind turbines. Marine Structures 61, 220-237.

Ruzzo, C., Failla, G., Arena, F., Collu, M., Li, L., Mariotti, A. 2019. Analysis of the coupled dynamics of an offshore floating multi-purpose platform, part B: hydro-elastic analysis with flexible support platform. Proceedings of the ASME $201938^{\text {th }}$ International Conference on Ocean, Offshore and Arctic Engineering, June 9-14, 2019, Glasgow, Scotland, UK. OMAE2019-96212.

The Blue Growth Farm website

https://www.thebluegrowthfarm.eu/. Accessed: June 2020.

Thiebaut, F., Pascal, R.C.R., Andreu, A.G. 2015. Investigation into the calibration of orifices used in OWC tank testing. Proceedings of the 11th European Wave and Tidal Energy Conference (EWTEC2015), September 6-11, 2019 Nantes, France. pp. 10B2-4-1. 